Laser Beam Propagation through Long Ignition Scale Plasmas on NIF

S. H. Glenzer

June 22, 2005

IEEE International Conference on Plasma Science Monterey, CA, United States June 20, 2005 through June 24, 2005 
This document was prepared as an account of work sponsored by an agency of the United States Government. Neither the United States Government nor the University of California nor any of their employees, makes any warranty, express or implied, or assumes any legal liability or responsibility for the accuracy, completeness, or usefulness of any information, apparatus, product, or process disclosed, or represents that its use would not infringe privately owned rights. Reference herein to any specific commercial product, process, or service by trade name, trademark, manufacturer, or otherwise, does not necessarily constitute or imply its endorsement, recommendation, or favoring by the United States Government or the University of California. The views and opinions of authors expressed herein do not necessarily state or reflect those of the United States Government or the University of California, and shall not be used for advertising or product endorsement purposes. 


\title{
LASER BEAM PROPAGATION THROUGH LONG IGNITION SCALE PLASMAS ON NIF *
}

\author{
Presentation to: \\ ICOPS, June 2005, Monterey, CA
}

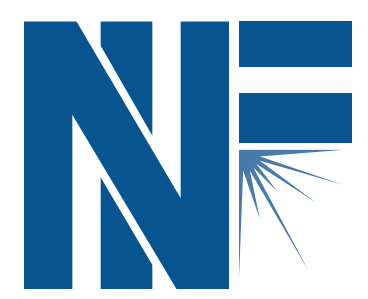

\section{Siegfried H. Glenzer}

\section{Lawrence Livermore National Laboratory}




\section{LASER BEAM PROPAGATION THROUGH LONG IGNITION SCALE PLASMAS ON NIF}

S. H. Glenzer, D. H. Froula, L. Divol, O. S. Jones, M. R. Dorr, C. Niemann, R. L. Berger, S. Langer

Lawrence Livermore National Laboratory, 7000 East Avenue, L-399, Livermore, CA USA

Experiments on the National Ignition Facility (NIF) have employed the first four beams to measure propagation and laser backscattering losses in large ignition-size plasmas. Gas-filled targets between $2 \mathrm{~mm}$ and $7 \mathrm{~mm}$ length have been heated from one side by overlapping the focal spots of the four beams from one quad operated at $351 \mathrm{~nm}(3 \omega)$ with a total intensity of $2 \times 10^{15} \mathrm{~W} \mathrm{~cm}^{-2}$. The targets were filled with 1 atm of $\mathrm{CO}_{2}$ producing of up to $7 \mathrm{~mm}$ long homogeneously heated plasmas with densities of $n_{e}=5 \times 10^{20} \mathrm{~cm}^{-3}$ and temperatures of $T_{e}=2 \mathrm{keV}$. The high energy in a NIF quad of beams of $16 \mathrm{~kJ}$, illuminating the target from one direction, creates unique conditions for the study of laser plasma interactions at scale lengths not previously accessible.

The propagation through the large-scale plasma was measured with a gated $\mathrm{x}$-ray imager that was filtered for $3.5 \mathrm{keV} \mathrm{x}$ rays. These data indicate that the beams interact with the full length of this ignition-scale plasma during the last $\sim 1 \mathrm{~ns}$ of the experiment when applying full laser beam smoothing consisting of phase plates, smoothing by spectral dispersion and polarization smoothing. Measurements that only apply phase plates show laser beam filamentation and reduced propagation speed. These results demonstrate the NIF experimental capabilities and further provide a benchmark for three-dimensional modeling of the laser-plasma interactions at ignition-size scale lengths.

* Work performed under the auspices of the U.S. Department of Energy by the University of California, Lawrence Livermore National Laboratory under contract no. W-7405-ENG-48 


\section{Outline}

- Introduction

- National Ignition Facility

- Experiment

- Laser Plasma interaction experiments on NIF

- $\quad$ Long Pulse Vacuum Hohlraum Performance on NIF

- Results

- $\quad$ Propagation through 7 mm plasmas

- Hohlraum temperature scaling verified on NIF

- Conclusions

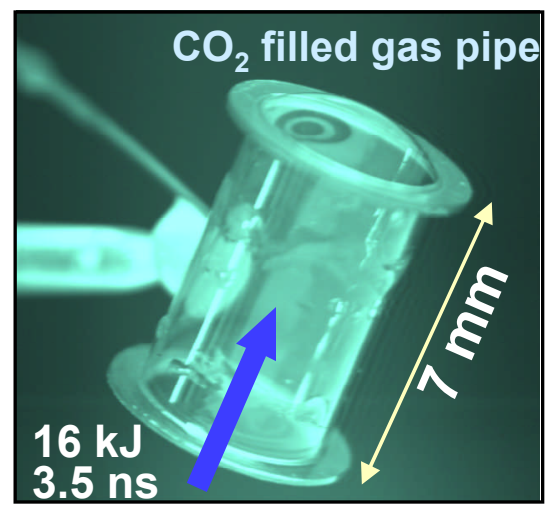
images showing beam propagation

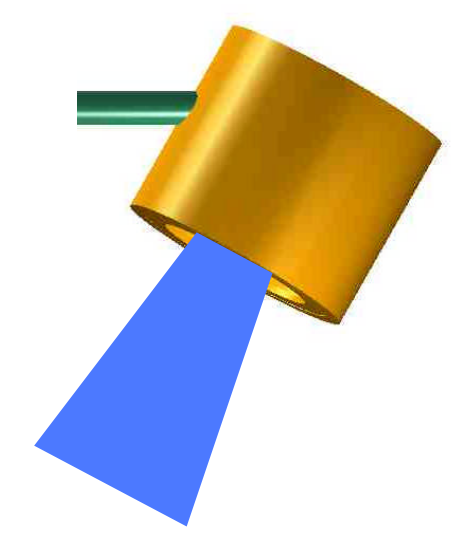




\section{On the first NIF experiments, we approach ignition size plasmas of $7 \mathrm{~mm}$ length to study nonlinear interactions}
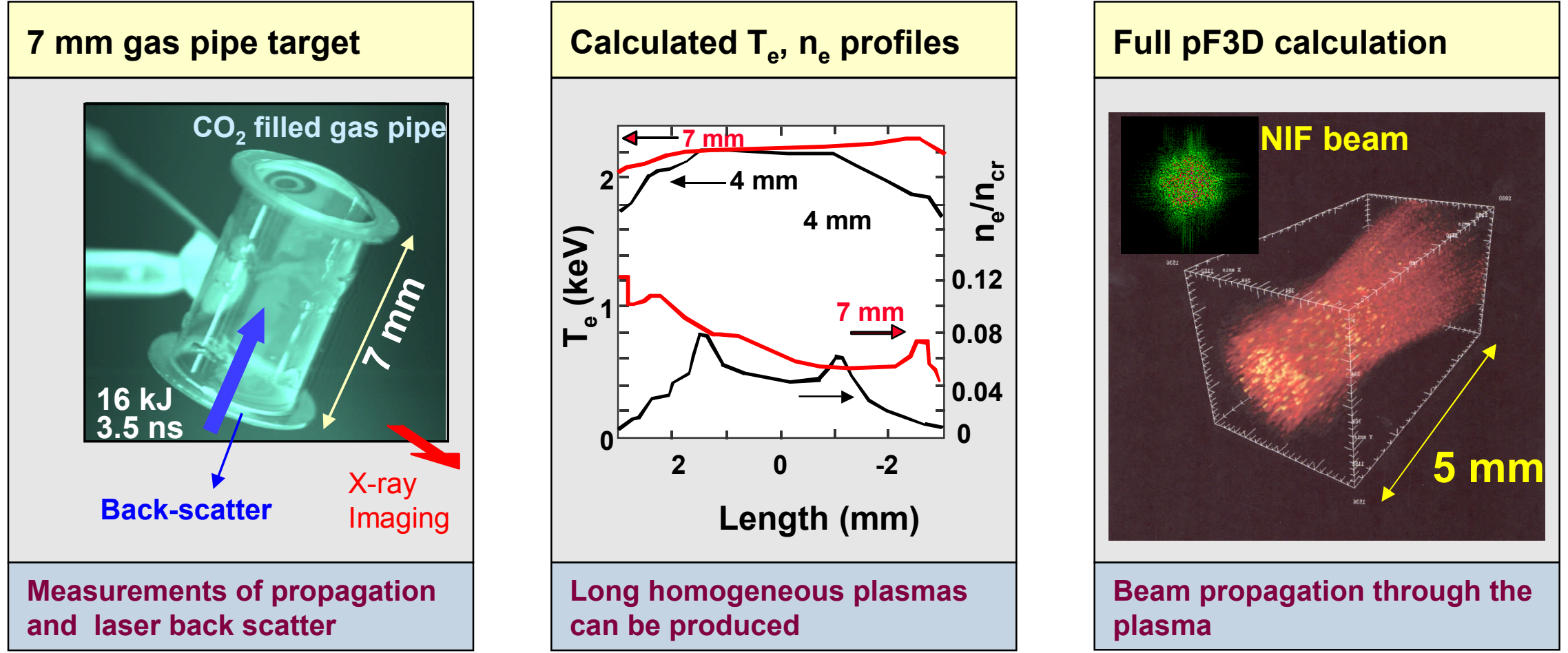

- $\quad$ Plasmas allow study of backscatter with length at $2 \times 10^{15} \mathrm{~W} \mathrm{~cm}^{-2}$

- not ignition surrogate ( $T_{e}$ lower, different species)

- Low- $T_{e}$ effects and filamentation (beam spray and self focusing) may be important

- Near backscatter imaging diagnostics was used to quantify scattering out side of FABS

- Effects of SSD and PS beam smoothing on beam propagation and stimulated scattering 
The first four NIF beamlines have been commissioned to the center of the target chamber

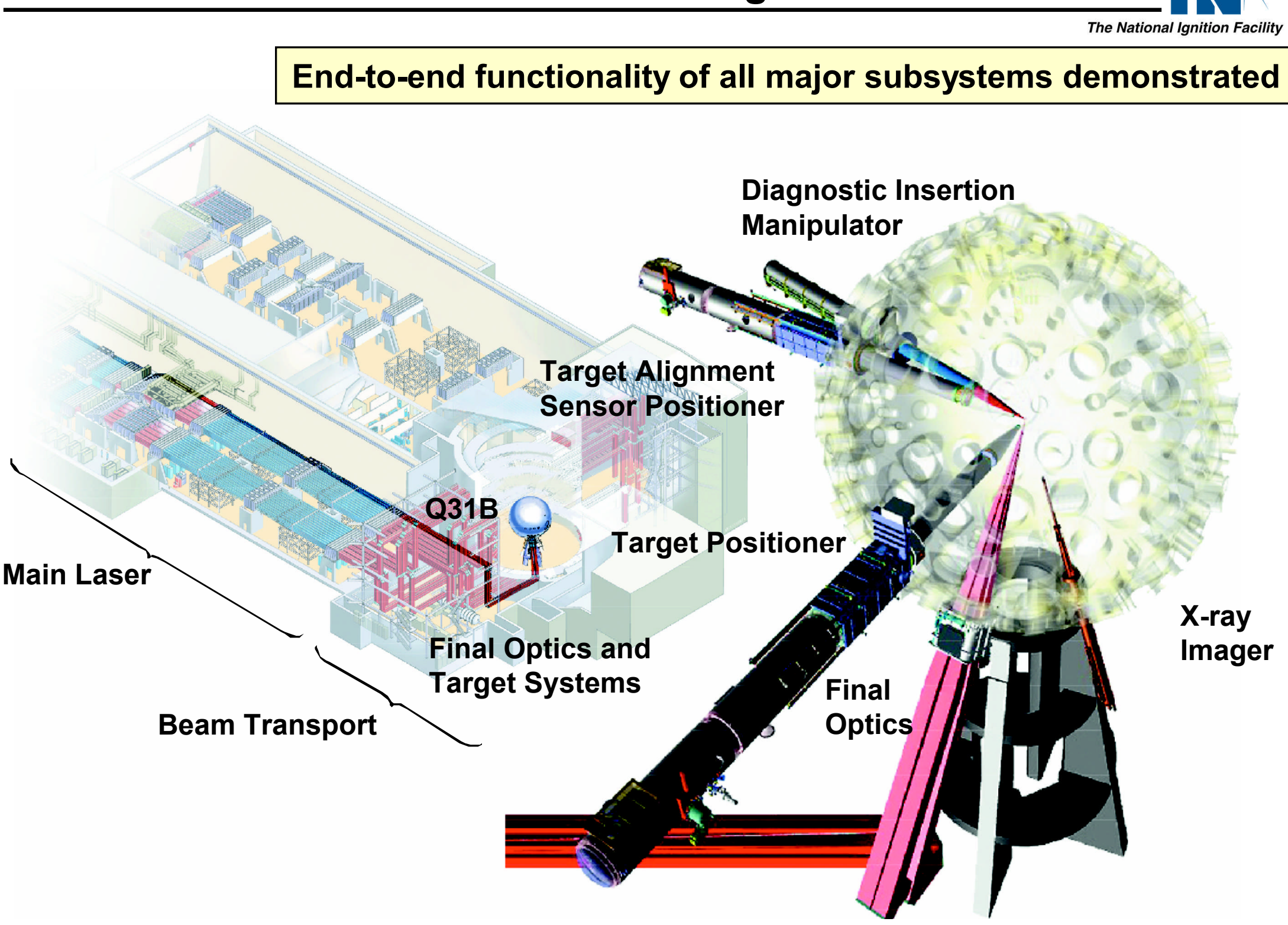


The NIF beams are arranged in groups of 4 beams (quads)

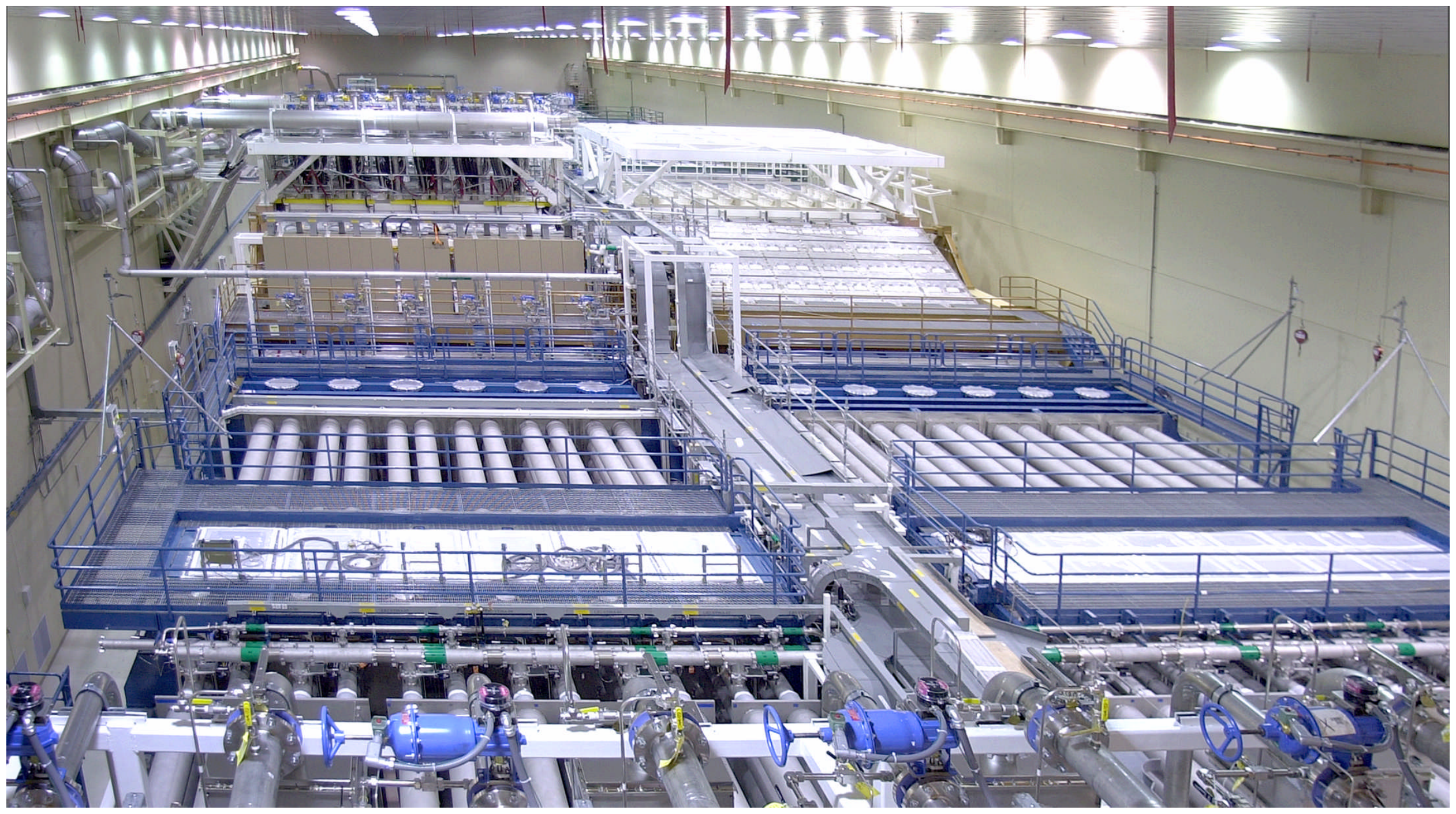




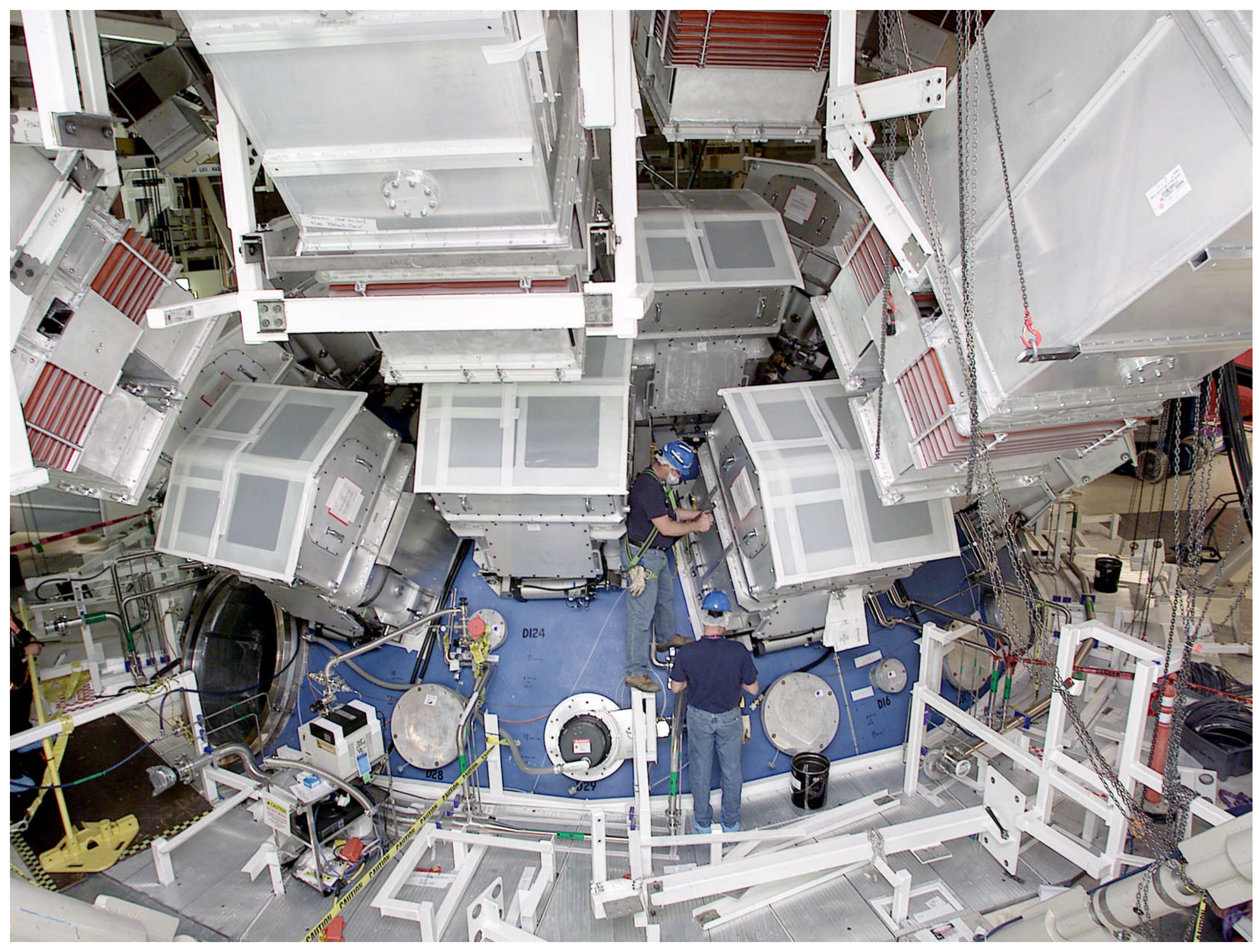


The first experiments on NIF have demonstrated control and suppression of filamentation in large scale plasmas

The National Ignition Facility
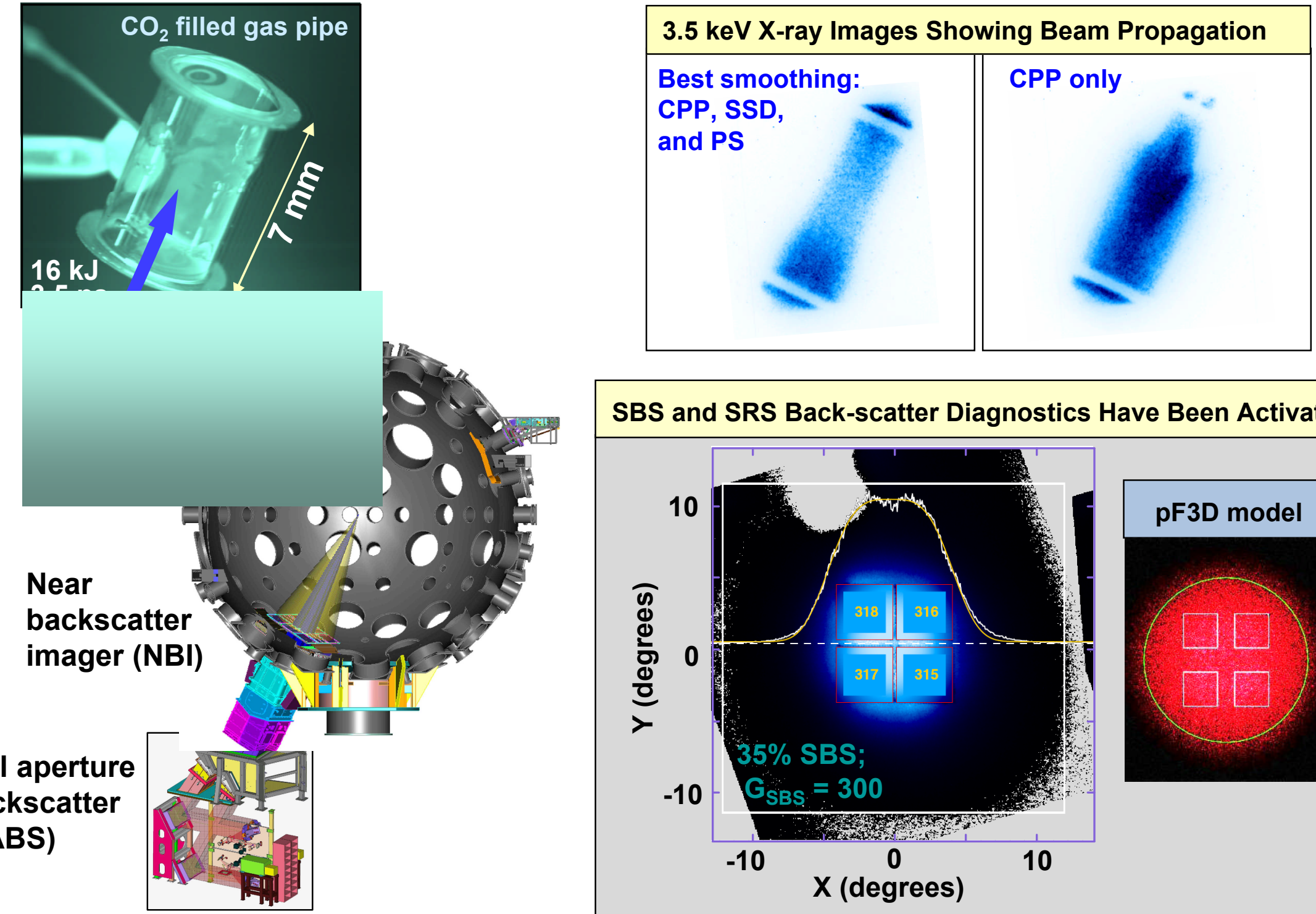

SBS and SRS Back-scatter Diagnostics Have Been Activated
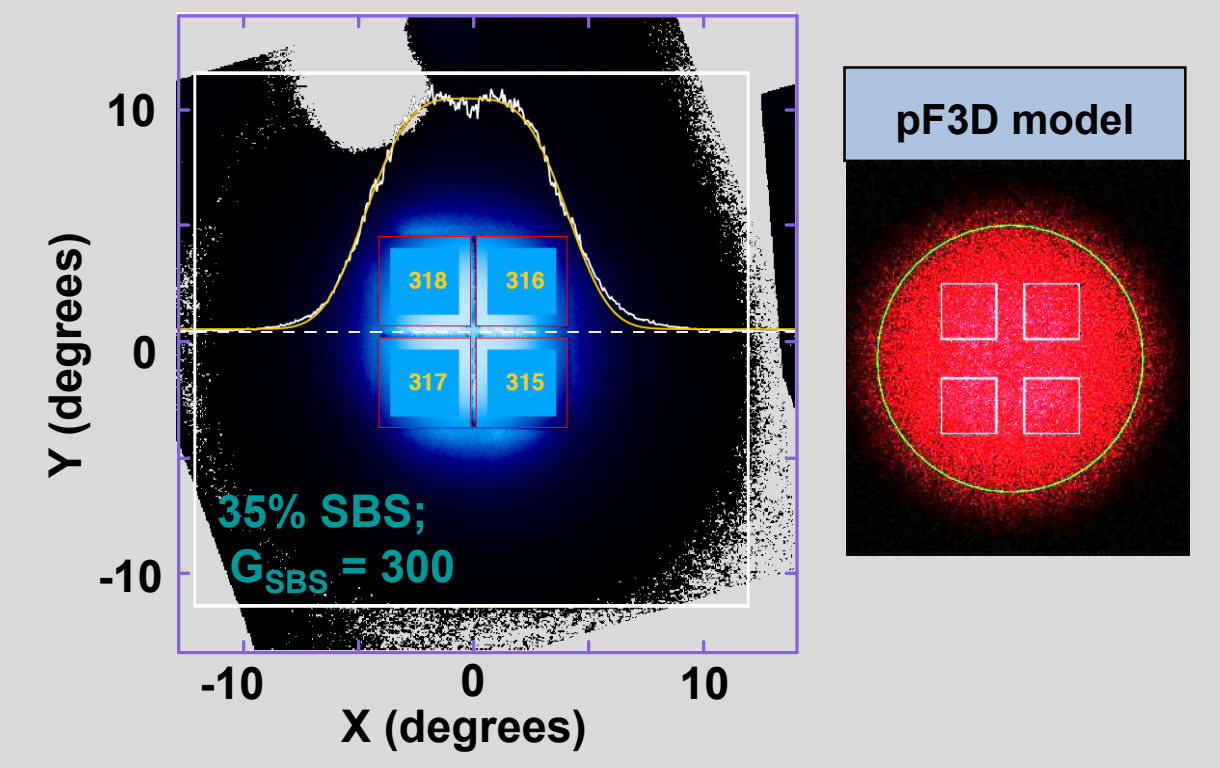
"Beam Smoothing" has several elements

\begin{tabular}{|c|c|c|}
\hline No CPP & With CPP & With SSD \\
\hline \multicolumn{2}{|c|}{ Stationary speckles } & Time-averaged pattern \\
\hline $\mid \begin{array}{ll}1 \mathrm{~mm} & \\
& \\
& \text { No SSD } \\
& \text { No CPP }\end{array}$ & 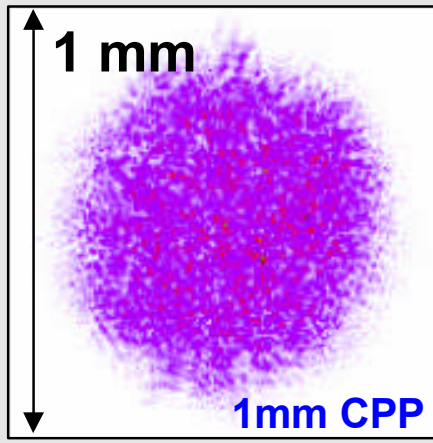 & $\begin{array}{l}\text { SSD } \\
\text { No CPP }\end{array}$ \\
\hline $\begin{array}{l}\text { CPPs determine } t \\
\text { the control intens }\end{array}$ & $\begin{array}{l}\text { t size and } \\
\text { tribution }\end{array}$ & $\begin{array}{l}\text { ves hot spots on } \\
\text { le scales ( } \sim 4 \mathrm{ps})\end{array}$ \\
\hline
\end{tabular}

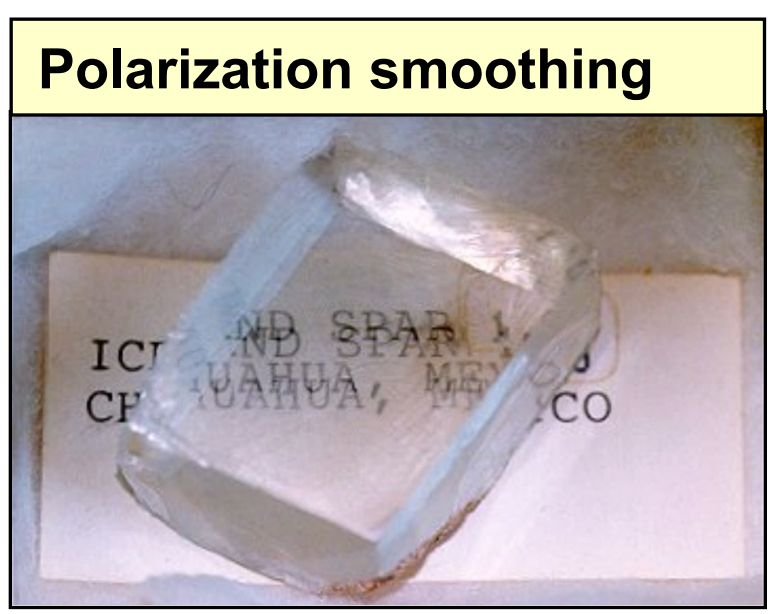

Polarization smoothing separates the speckles giving instantaneous $\sim \sqrt{2}$ speckle intensity reduction 


\section{X-ray measurements of laser beams with PS, SSD indicate ideal propagation and agree with calculations to $0.3 \mathrm{~ns}$}
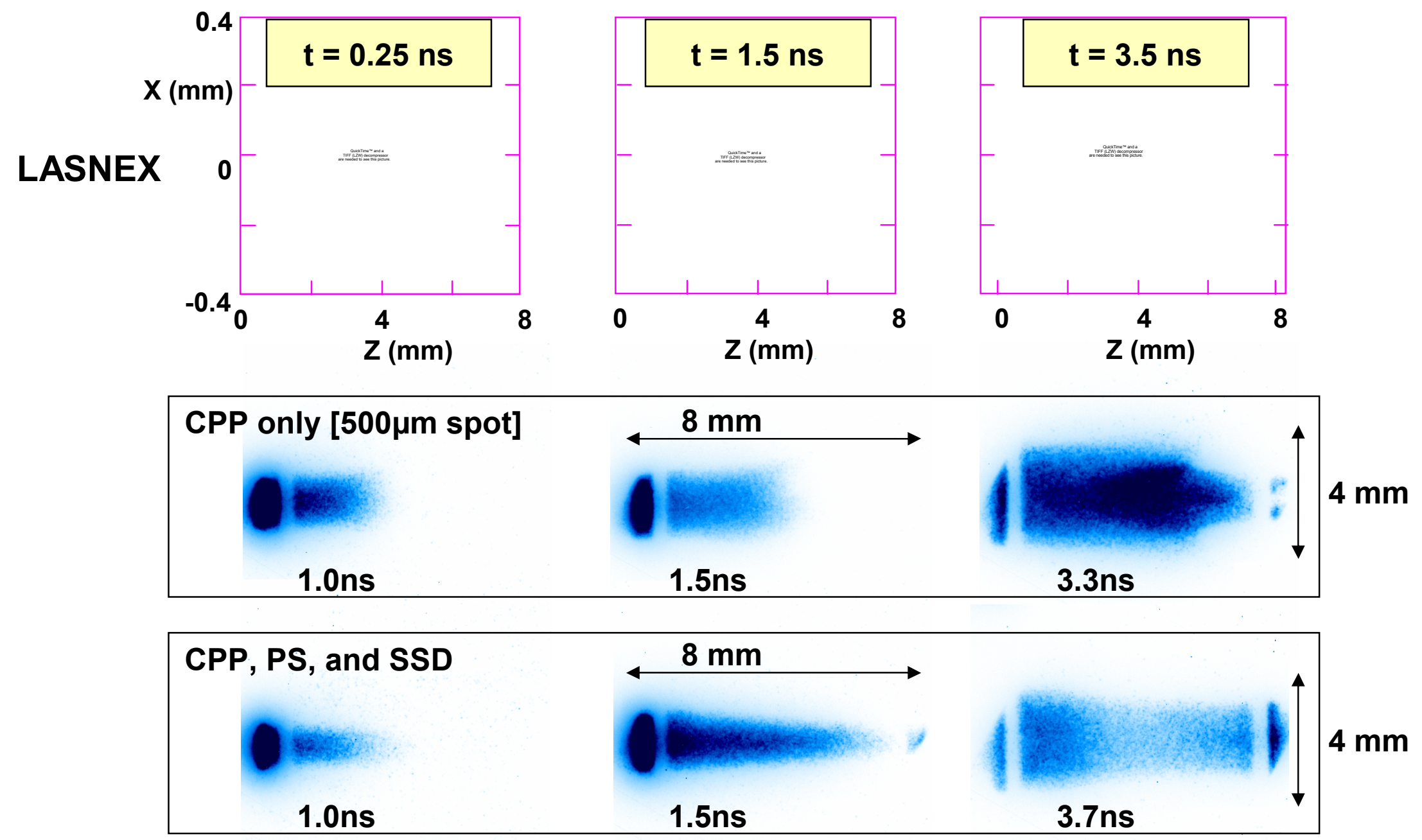

These propagation measurements are unique to NIF These smoothing options will be fielded on full NIF ignition 

Calculations with laser speckles and ponderomotive effects
show improved propagation consistent with data

Results

The National Ignition Facility
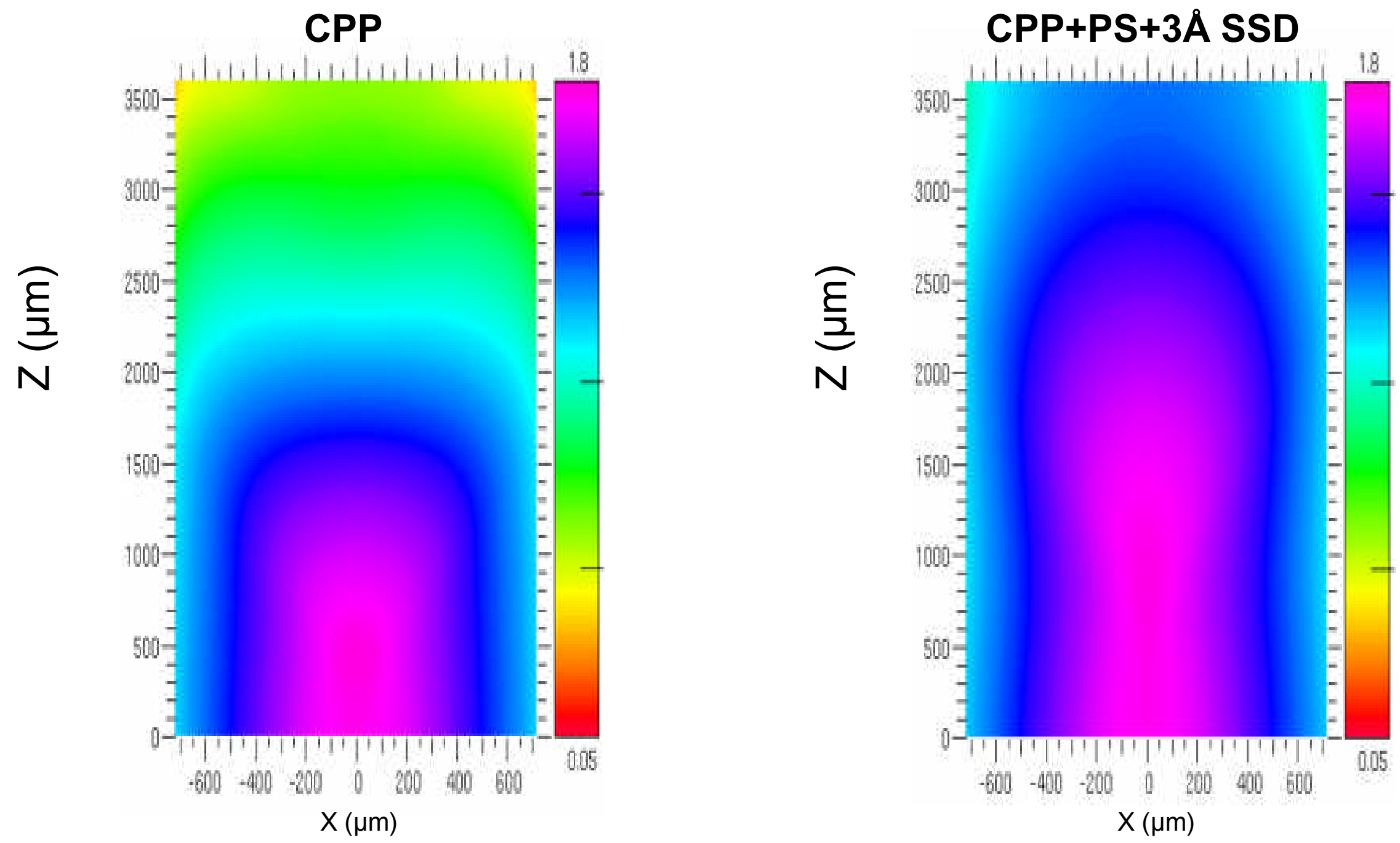

After $1 \mathrm{~ns}$, the fully smoothed beam has burnt through $1 \mathrm{~mm}$ farther 
The NBI plate was calibrated at $351 \mathrm{~nm}$ and $527 \mathrm{~nm}$ and shown to be constant within $\pm 10 \%$

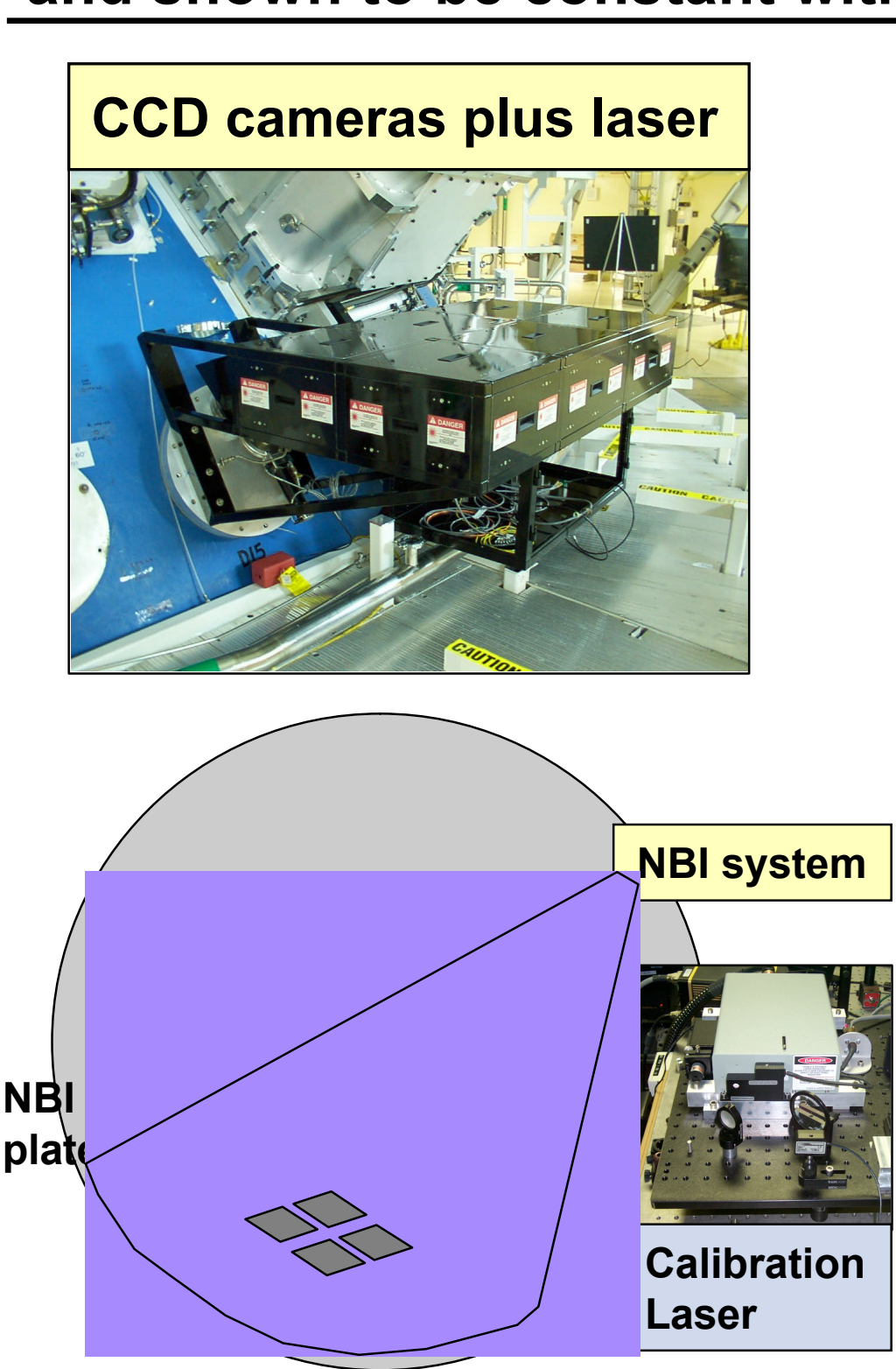

The National Ignition Facility

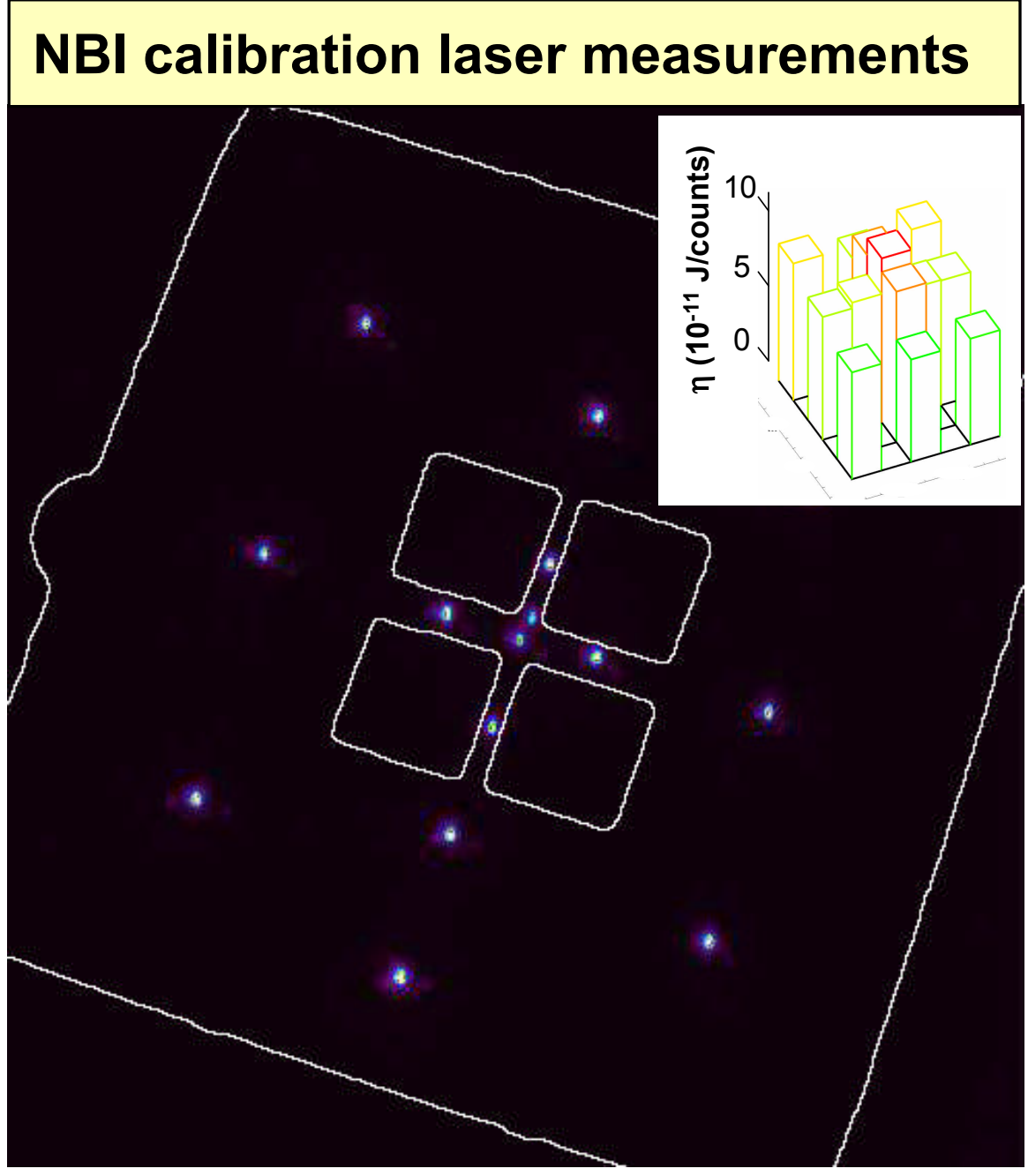

- Sensitivity is slightly lower on the vertical cross - Sensitivity is the same with and without acrylic 
SBS Near backscatter imager shows more spray on shots without PS consistent with $\mathrm{X}$-ray propagation
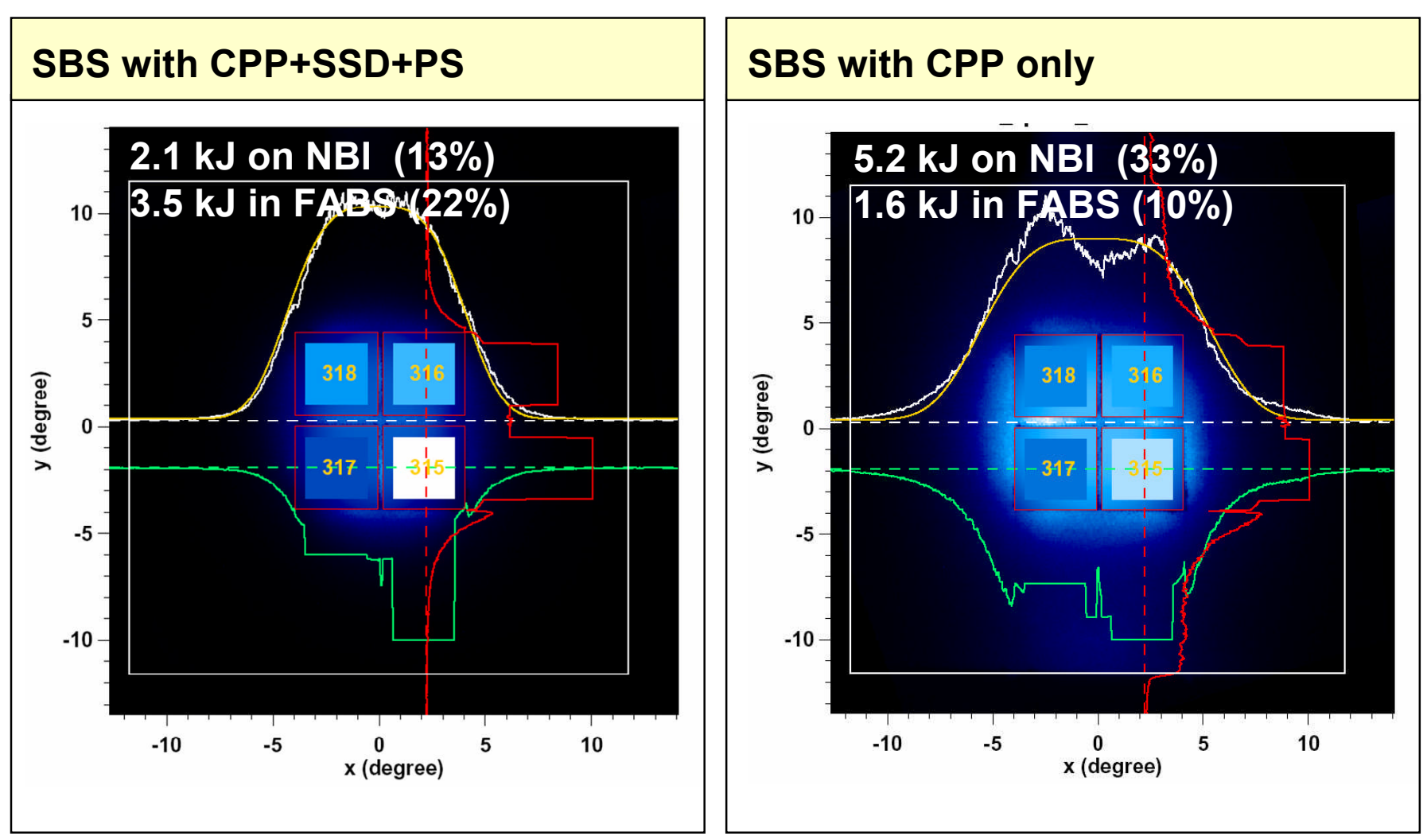

The National Ignition Facility

Results

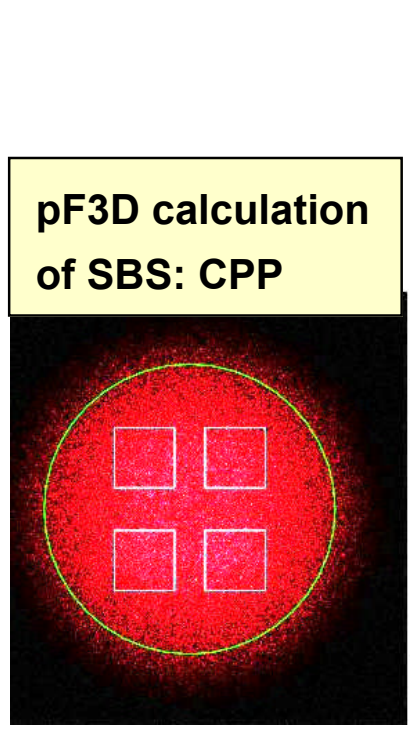

- $\quad$ SRS is negligible

- $\quad$ SBS Backscatter is more collimated with full beam smoothing

- Spatial extend on scatter plate is reduced

- Larger contribution into FABS

- Calculations slightly overestimate the amount of beam spray 
The dependence of backscatter on plasma length shows nonlinear growth

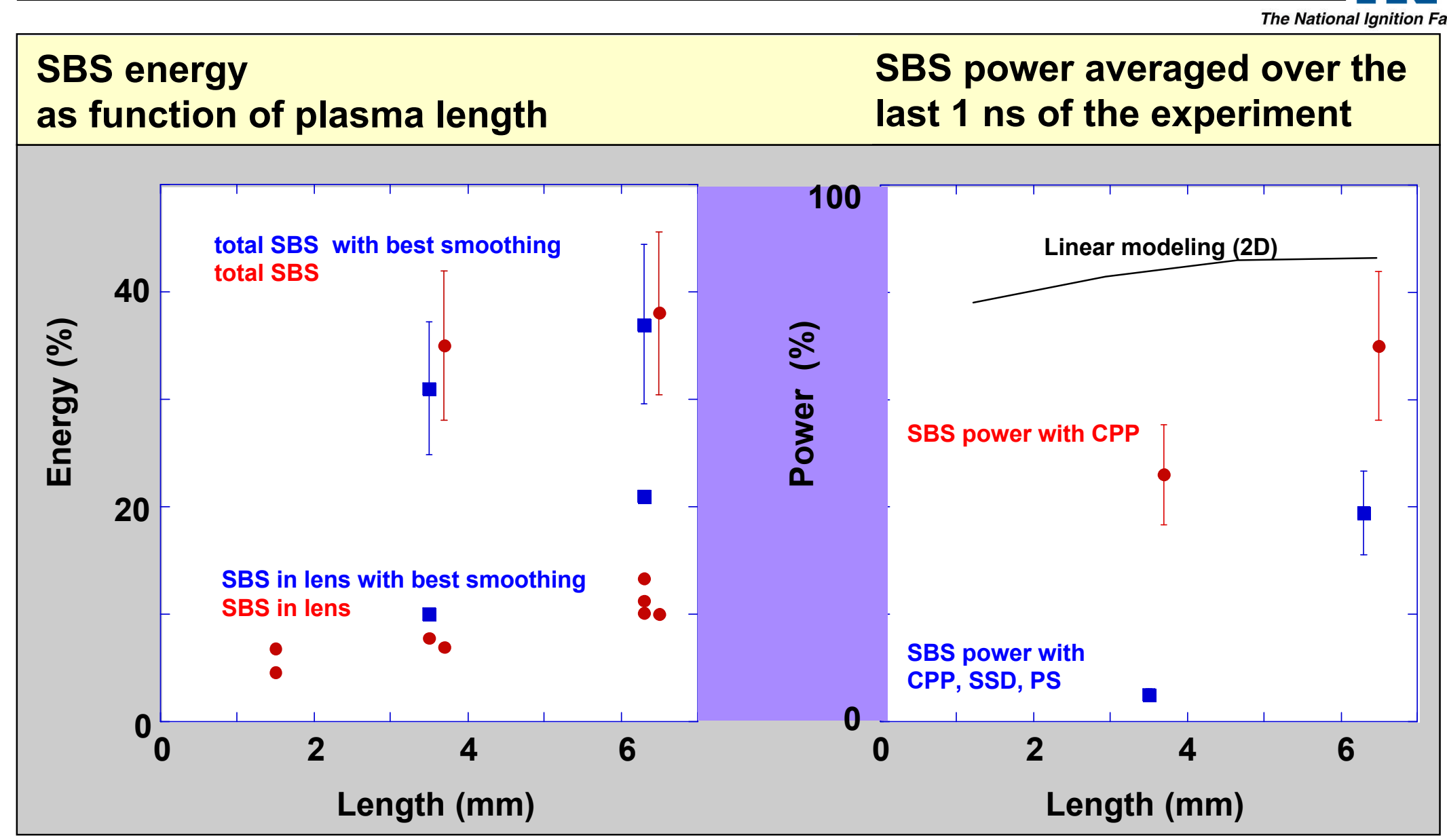

- We are in the process of modeling the backscattered SBS power

- To understand these results it will be important to properly model

- Beam propagation, Filamentation, Nonlinear (kinetic) saturation processes

- Goal: predictive modeling for laser-plasma interactions in ignition conditions 
An international team has successfully activated hohIraum drive capability and related diagnostics at NIF

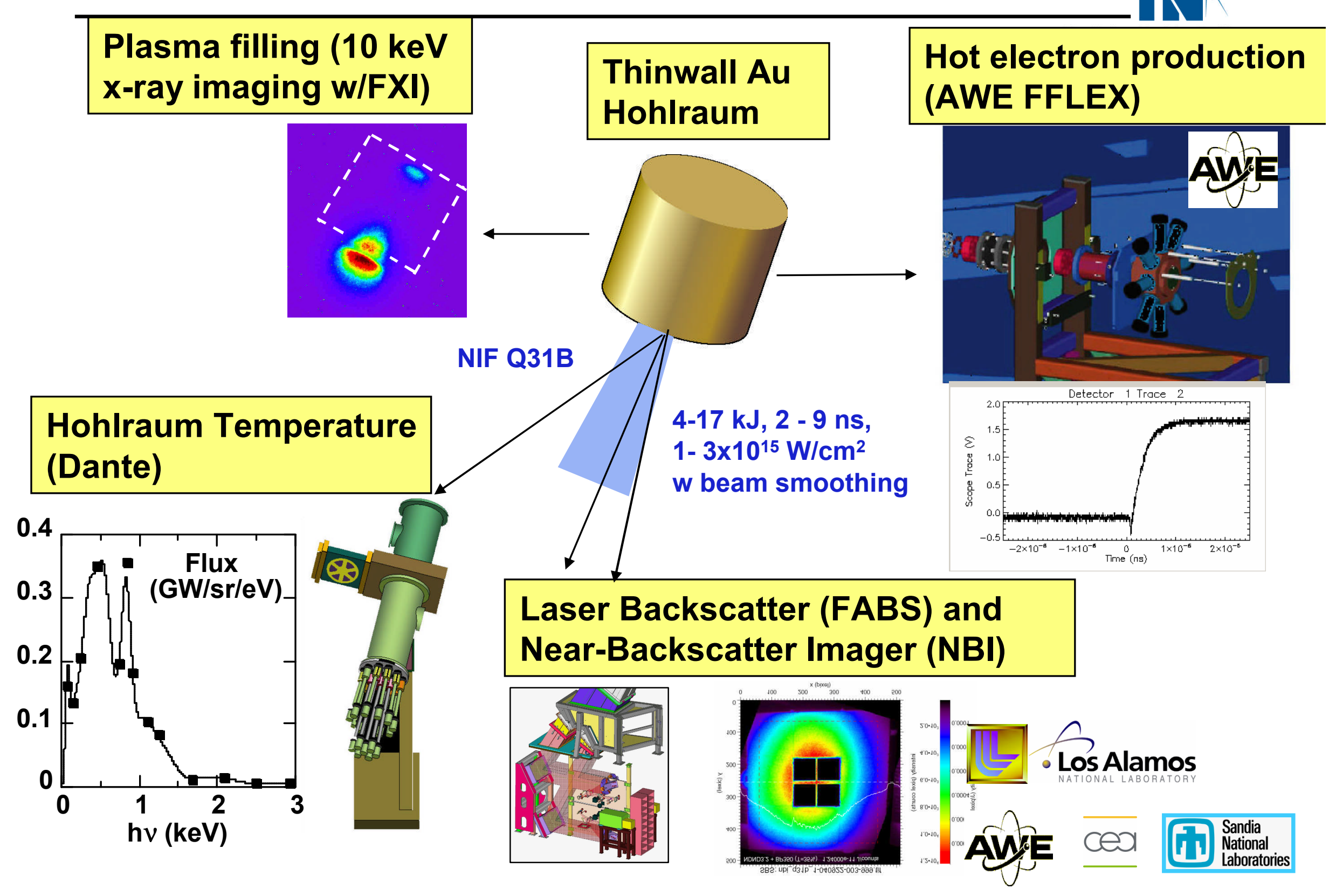




\section{Conclusions}

- Large scale length laser plasma experiments on NIF have demonstrated the importance of beam smoothing

- $\quad$ Beams propagate through $7 \mathrm{~mm}$ of plasma with CPP, SSD, and PS

- $\quad$ Backscatter during the last 1ns of the experiment is strongly affected by smoothing

- It will be important to understand the late time SBS behavior

- The first hohlraum experiments on NIF have shown $T_{\text {RAD }}>300 \mathrm{eV}$

- Hohlraum diagnostics activated

- $\quad$ Results are in good agreement with modeling

- $\quad$ No significant backscattering

- Future experiments may include

- Gas-filled hohlraums versus lined hohIraums

- Cocktails versus gold hohlraums

- $\quad$ Relative merit of PS and SSD 